\title{
GECA apuesta por una Coordinadora de Profesionales de la Cultura
}

Con una propuesta interesante y, en cierta medida, urgente: promover un encuentro entre las distintas asociaciones de profesionales que existen en la comunidad autónoma andaluza y cuyo trabajo incide en la gestión de la cultura; la Asociación de Gestores Culturales de Andalucía (GECA) aprobó en Junta Directiva participar en Mercartes 2006. Fue en este encuentro, celebrado en noviembre del pasado año, donde surgió la idea de crear una Coordinadora de profesionales que articule a los distintos colectivos para que puedan participar con una visión profesional, crítica y constructiva en los distintos procesos de política cultural.

Para esta primera reunión, que tuvo lugar el 16
de noviembre en la Sala Mojácar de FIBES, en el
marco de la programación de Mercartes 2006,
fueron convocados asociaciones de antropólo-
gos, archiveros, documentalistas, museólogos,
bibliotecarios, gestores culturales, gestores y
empresas de artes escénicas, creadores de artes
y actuaciones culturales emergentes (comics,
grafitis...), etc., así como representantes de

๑ Katastroff Circus. La Pulga Teatro. IX Festival de Música y Teatro Sacro-Ritual de Riogordo. Málaga / Dolores Lobillo Aranda

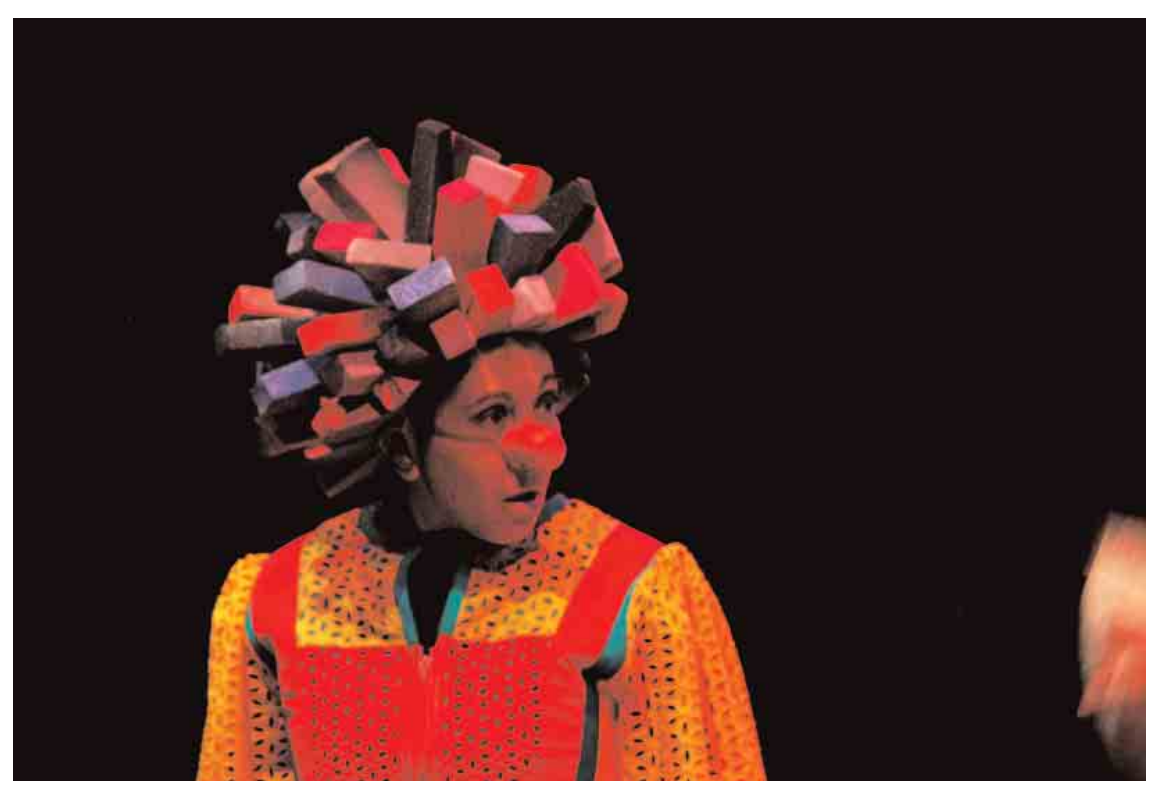

ACTA, UNIMA, Escenarios de Sevilla, E-Veleta, OIKOS, PLACA, ATAES Y GECA.

El entonces vicepresidente de GECA, Rafael Morales Astola, explicó las líneas generales que se han seguido a lo largo, especialmente, de los últimos tres años, bajo la presidencia de M $^{2}$ Isabel Sagrera:

$\rightarrow$ Apoyo creciente a la formación, como se refleja en las intensas relaciones con IAPH, CEA, Universidades de Sevilla y de Granada, Consejería de Cultura y Escénic@.

$\rightarrow$ Relanzamiento de la Federación Estatal de Asociaciones Profesionales de la Gestión Cultural.

$\rightarrow$ Interacción con diversas entidades e instituciones, proponiéndose GECA como elemento catalizador y fomentador de sinergias a la hora del intercambio de información y de generación de ideas.

En función de esta tercera línea, se acometió la iniciativa de reunir a los colectivos profesionales de la cultura y articular una posición integradora, abierta y democrática, que pueda participar con una visión profesional, crítica y constructiva en los distintos proce- 
(- Público del IX Festival de Música y Teatro Sacro-Ritual. Riogordo, Málaga / Dolores lobillo Aranda

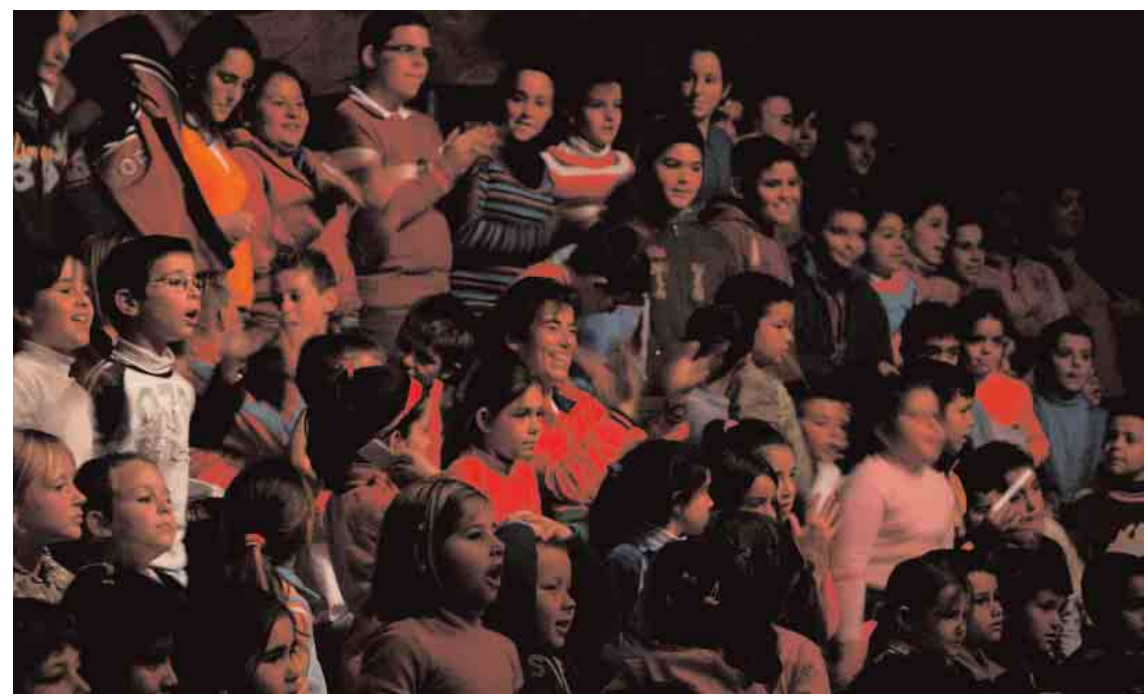

sos de política cultural en nuestra comunidad autónoma

Tras un interesante debate sobre todos los aspectos de la realidad andaluza (economía, empleo, calidad de los productos y su distribución, relaciones del sector público con el sector privado, diversidad de las artes y de los modelos de gestión, etc.), surgieron una serie de propuestas:

$\rightarrow$ Linkear las páginas Web de las asociaciones presentes en la reunión como manera de fomentarse los unos a los otros y de dar un primer impulso al intercambio de información desde las nuevas tecnologías.

$\rightarrow$ Crear una Coordinadora que obligue a celebrar reuniones periódicas para tratar de los asuntos que más interesen y elaborar respuestas conjuntas, promoviendo además la constitución de fines comunes ante el desarrollo cultural de la comunidad autónoma.

$\rightarrow$ Fijar nuevos encuentros como el de Mercartes, aprovechando el calendario de festivales y ferias culturales existentes en Andalucía.

$\rightarrow$ Redactar un Acta de la reunión en Mercartes que sirva como posible documento fundacional de la Coordinadora futura.
(- Montaje de La Carpa de Pizarra en Riogordo / Dolores lobillo Aranda

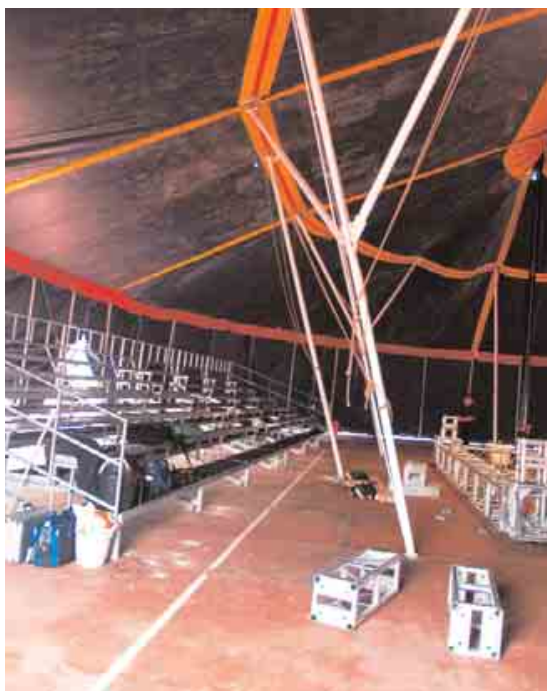

ción del Plan Estratégico para la Cultura en Andalucía (PECA), al tiempo que se establecían otros tales como dignificar al profesional del sector cultural, solicitar una mayor divulgación en medios publicitarios de la cultura, promover la aplicación del 1\% de los presupuestos de todas las instituciones a la cultura, regularizar los epígrafes en hacienda y potenciar la formación académica superior de todas las disciplinas de las asociaciones de la Coordinadora.

En la tercera convocatoria, actualmente en preparación, está previsto que las asociaciones presenten su "ficha-modelo" descriptiva (la base para empezar a trazar acciones y objetivos comunes), y que se decidan la estructura definitiva de la Coordinadora, el objetivo común que se considere más urgente y una ruta de contactos, tanto instituciones públicas como privadas, a las que presentarse. culares). Igualmente se reflexionó sobre la conveniencia de definir el perfil del asociado a la Coordinadora, que debe aglutinar a asociaciones profesionales que trabajan por la cultura, con sede en Andalucía o con ámbito de trabajo andaluz en primer instancia.

En la búsqueda de objetivos comunes, destacó el de participar en el seguimiento y aplica-
Rafael Morales Astola

Presidente de GECA 